\title{
Superabsorbent Polymers as a Means of Improving Frost Resistance of Concrete
}

\author{
Hasholt, Marianne Tange; Jensen, Ole Mejlhede; Laustsen, Sara
}

Published in:

Advances in Civil Engineering Materials

Link to article, DOI:

10.1520/ACEM20150012

Publication date:

2015

Document Version

Early version, also known as pre-print

Link back to DTU Orbit

Citation (APA):

Hasholt, M. T., Jensen, O. M., \& Laustsen, S. (2015). Superabsorbent Polymers as a Means of Improving Frost Resistance of Concrete. Advances in Civil Engineering Materials, 237-256.

https://doi.org/10.1520/ACEM20150012

\section{General rights}

Copyright and moral rights for the publications made accessible in the public portal are retained by the authors and/or other copyright owners and it is a condition of accessing publications that users recognise and abide by the legal requirements associated with these rights.

- Users may download and print one copy of any publication from the public portal for the purpose of private study or research.

- You may not further distribute the material or use it for any profit-making activity or commercial gain

- You may freely distribute the URL identifying the publication in the public portal

If you believe that this document breaches copyright please contact us providing details, and we will remove access to the work immediately and investigate your claim 
This is a preprint of an article published in Advances in Civil Engineering Materials:

Hasholt, Marianne T., Jensen, Ole M., and Laustsen, Sara,

"Superabsorbent Polymers as a Means of Improving Frost Resistance of Concrete," Advances in Civil Engineering Materials, Vol. 4, No. 1, 2015, pp. 237-256,

doi:10.1520/ACEM20150012. ISSN 2165-3984

The published version is available online:

http://compass.astm.org/DIGITAL LIBRARY/JOURNALS/ACEM/PAGES/ACEM20150012.htm 
1

2

3

4

5

6

7

8

9

10

11

\title{
Superabsorbent Polymers as a Means of Improving Frost Resistance of Concrete
}

Marianne T. Hasholt, Ole M. Jensen \& Sara Laustsen

\begin{abstract}
Superabsorbent polymer (SAP) was introduced in cementitious materials about 15 years ago. Since then, several studies on the frost resistance of concrete with SAP have been published. However, an up-to-date review across the different studies is missing. The present paper presents a literature review on how SAP influences concrete frost resistance. Moreover, it also presents a larger experimental study on the topic. The conclusions that can be drawn from the experimental study are in line with the extract of the pool of results from the literature, first of all that SAP addition can improve frost resistance of concrete. The improvement can be attributed to voids created by SAP. As clearly demonstrated in the paper, it is crucial to document the void structure of the hardened concrete. Other factors than SAP can lead to void formation. For example, residue of surfactant on SAP particles, originating from the production of suspension polymerized SAP, can have an air entraining effect in concrete. Therefore, assuming that SAP generated voids are the only voids may lead to erroneous conclusions. When SAP is used, it is - in principle - possible to produce concrete with a predefined void structure as regards total void volume and void size. However, the optimum SAP void structure in relation to frost resistance is not known, and as long as the target is not clear, it is hard to use the design option of controlled void structure in a constructive way.
\end{abstract}

Keywords: Concrete; Internal curing by superabsorbent polymer (SAP); Frost resistance 


\section{Introduction}

Superabsorbent polymer (SAP) is the generic term for a group of materials that can absorb a large quantity of specific substances from the surroundings. Most SAPs are designed to absorb water, and some types of SAP are capable of absorbing an amount of water that is more than 1000 times the mass of the dry SAP. [1].

When dry SAP particles are added to fresh concrete during mixing, they will absorb part of the mixing water. The absorption will cause swelling of the SAP particles, which then become finely distributed water reservoirs in the cement paste. Far the majority of the water held by SAP is so loosely bound that even a slight lowering of the relative humidity $(\mathrm{RH})$ in its vicinity will lead to water release and de-swelling of the SAP particles. In concrete, a reduction of RH normally occurs during hardening. A reduction of $\mathrm{RH}$ after setting, when the concrete is no longer plastic, will therefore generate small, air-filled cavities in the hardened cement paste. [2].

It was already discovered in the 1930s that air voids are beneficial for concrete frost resistance [3]. With SAP particles' ability to create cavities, it seems straightforward that SAP can be used to create air void systems in concrete, where there is a requirement for frost resistance. It is not only possible accurately to control the total volume of voids, it is also possible to control void size and void shape through the added SAP particles. As such, SAP may offer an attractive alternative to traditional air-entraining admixtures (AEA), since in concrete production it is often a challenge to control total air content and other air void parameters when using air-entraining admixtures. 
In recent years, about a dozen publications have been published, where SAP has been used in an attempt to improve the frost resistance of concrete [4-14]. The publications either aim directly at using SAP to engineer concrete with specific properties in relation to freezing and thawing, or SAP is used in concrete for other purposes such as internal curing to mitigate autogenous shrinkage, and then a range of properties including frost resistance are tested for the resulting concrete.

The scientific objective of the present paper is twofold:

1. The paper will review the cumulated knowledge on frost resistance of concrete with SAP. This is presented in section 2 .

2. Recently, our research group discovered that suspension polymerized SAP may contain a surfactant originating from the SAP production $[14,15]$. When SAP is added to concrete this surfactant is released and acts as air-entraining admixture and creates extra air voids. Therefore it is recommended that air void analysis of the hardened concrete is part of the experimental program, when investigating the properties of concrete with SAP. Only in this way it is possible to conclude if a change in the property is directly related to SAP addition or if it is related to the air entrained as a secondary effect. The air void analysis is especially important, when the investigated property is dependent on air content, air void structure, or both. This is in particular true for frost resistance of concrete. In this paper, we will take our own medicine and examine some of our previous results on frost resistance of concrete with SAP, where air void analysis was not originally performed [7]. The test results including a newly conducted air void analysis are here (re-)evaluated, see section 3. 


\section{Literature Review}

A RILEM technical committee working with SAP (RILEM TC 225-SAP) published a state of the art report in 2012. However, the chapter on concrete durability [10] was prepared almost two years before publication of the full state of the art report, and therefore it only covers references up to 2010 (references [5-8] of this paper). Considering the considerable additional knowledge acquired in the period 2010-2015, it seems timely with a new literature review.

When comparing results from different references describing the frost resistance of concrete with SAP, there are especially three aspects, which have to be considered: the type of SAP, the mix design (especially w/c), and the actual test methods. These three aspects are explained in further detail below.

\subsection{Type of SAP}

SAP production can be grouped into two types [1]:

- In the bulk solution polymerization process a monomer mix is put into a reaction vessel where it forms a gel. The gel is dried either as a whole or in smaller pieces. After drying, the gel is grounded to obtain the desired SAP particle size.

- In the suspension polymerization process a monomer or a solution containing a monomer is by stirring held as suspended droplets within a continuous, inert liquid phase. Normally the droplets are stabilized against coalescence by addition of a suspension aid. The polymerization process takes place in each droplet. The size and shape of the droplets and consequently also the final SAP particles depend on both stirring intensity and the type and amount of suspension aid. Increasing amounts of suspension aid and increasing 
stirring intensity result in smaller SAP particles. In the end, the created SAP particles are isolated from the fluid, e.g. by filtration followed by drying.

Bulk solution polymerization results in SAP particles with irregular shape, whereas suspension polymerization usually results in spherical particles. The shape of the cavities created by SAP in concrete are identical to the shape of the dry SAP particles, the only difference being the larger size of the cavities due to swelling of SAP by water absorption.

\subsection{Mix Design for Concrete with SAP}

When dry SAP particles are added to a concrete mix, they will absorb some of the mixing water. This happens within a few minutes after they get in contact with water. When a reference concrete mix without $\mathrm{SAP}$ is compared to a concrete mix with SAP, it is important to note if the SAP is added with or without extra water to compensate the absorption of mixing water, see example in Fig. 1.

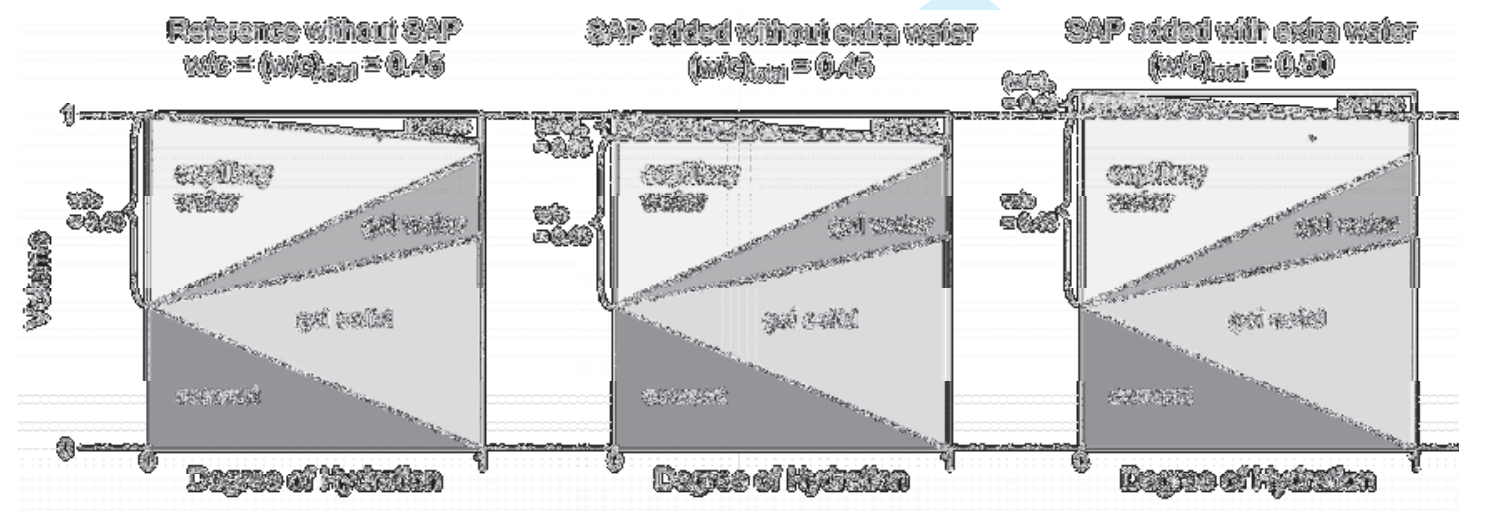

Fig. 1: Powers' diagram for sealed cement paste in three different situations, which demonstrates the difference between $w / c,(w / c)_{e}$, and $(w / c)_{\text {total. }}$ Left: Cement paste without SAP (reference), w/c=0.45. Center: Cement paste with SAP added, but without extra water. 
Right: Cement paste with SAP and extra water added equivalent to the amount absorbed by SAP. In both cement pastes with SAP, SAP absorbs water equivalent to $(w / c)_{e}=0.05$.

The theoretical background for water-entrained concrete with SAP is explained in [2]. The implications of adding SAP with or without extra water to counterbalance the SAP absorption is explained in the following, where the variables $\mathrm{w} / \mathrm{c},(\mathrm{w} / \mathrm{c})_{\mathrm{e}}$, and $(\mathrm{w} / \mathrm{c})_{\text {total }}$ all refer to the state of the fresh concrete after possible SAP particles have absorbed part of the mixing water:

- $\mathrm{w} / \mathrm{c}$ is the water/cement ratio of the fresh cement paste surrounding possible SAP particles

- $(\mathrm{w} / \mathrm{c})_{\mathrm{e}}$ is the amount of water held by SAP relative to the cement mass of the system (index "e" refers to entrained water, using same nomenclature as for internal curing)

- $(\mathrm{w} / \mathrm{c})_{\text {total }}$ is the total amount of water relative to cement mass; $(\mathrm{w} / \mathrm{c})_{\text {total }}=\mathrm{w} / \mathrm{c}+(\mathrm{w} / \mathrm{c})_{\mathrm{e}}$

If SAP is added without extra water, the w/c of the cement paste is reduced. In the example in Fig. 1 (center), the w/c is reduced from 0.45 to 0.40 . The total porosity of the two systems is identical. For the system with SAP, SAP created voids are part of the total porosity. In the beginning, they are liquid-filled, but they are gradually emptied during hydration. As regards e.g. transport phenomena, the total porosity is not governing, as very little transport takes place in relatively large, air-filled voids. It is the porosity of the cement paste surrounding the SAP voids (and the tortuosity of the pore system) that is governing. It can be seen that the porosity of the cement paste surrounding the SAP voids is less than the porosity of the reference paste. This is most pronounced at an advanced stage of hydration.

If SAP is added with extra water, the w/c of the cement paste excluding SAP voids is identical for the system with SAP (Fig. 1, right) and the reference system (Fig. 1, left). The total 
porosity of the system with SAP is larger than the total porosity of the reference, but for equal degree of hydration the porosity of the paste surrounding the SAP voids is identical to the porosity of the paste of the reference. Therefore, the paste surrounding the SAP voids is expected to have e.g. transport properties similar to the paste of the reference.

For $\mathrm{w} / \mathrm{c}<0.42$, the availability of water may be a constraint for which reason full hydration cannot be reached. If SAP is added without extra water, the maximum degree of hydration is identical to the maximum degree of hydration of the reference, but if SAP is added with extra water, the concrete may experience a higher degree of hydration due to the entrained water.

As documented by many authors, e.g. Powers [16], frost resistance of concrete can be improved both by introducing an adequate air void system and by lowering the w/c. If concrete with SAP and no extra water shows better frost resistance than a reference concrete without SAP, it may be difficult to conclude if the positive effect of SAP is due to the formation of voids or due to the lower $\mathrm{w} / \mathrm{c}$ ratio.

\subsection{Test Methods}

There are many national and international test methods to evaluate concrete frost resistance, where the concrete specimens are exposed to consecutive freezing and thawing cycles to accelerate the development of damage. Frost deterioration may appear as external damage in the form of surface scaling and as internal damage in the form of cracking. Therefore, test methods related to the ability to withstand freezing and thawing can be divided into two major groups: 
- Test methods, where the extent of external damage is measured. This can be done either by visual rating of a damaged surface or by collecting and quantifying the amount of material scaled off.

- Test methods, where the extent of internal damage is measured. When concrete cracks during frost action, the cracking is normally associated with expansion. The cracks also become an obstacle for sonic waves. Therefore, the development of internal damage can be observed through measurements of e.g. length change or ultrasonic pulse transition time, where the later can be related to the dynamic elastic modulus. Alternatively, internal cracking can be visually evaluated on epoxy impregnated plane sections, but here the cracking is difficult to quantify.

In Europe, testing is usually based on observation of external damage, and there is now a European technical specification for this, CEN/TS 12390-9 [17]. The reference method of this specification is very similar to the Swedish test standard SS 137244 [18]. The so-called CDF-test (Capillary Suction, De-icing agent and Freeze-thaw-test [19]) developed by a RILEM technical committee is an alternative method of CEN/TS 12390-9.

Air void analysis of hardened concrete according to methods such as EN 480-11 [20] and ASTM C457 [21] can give information supplementary to the accelerated freeze/thaw test.

\subsection{Results Reported in the Literature}

Table 1 gives an overview of publications, which contain results from experimental investigation of the frost resistance of concrete with SAP. 
Table 1: Overview of publications on frost resistance of concrete with SAP.

\begin{tabular}{|c|c|c|c|}
\hline Ref. & Type of SAP & Mix composition of tested concrete & Test method \\
\hline $\begin{array}{l}{[4]} \\
{[5]^{\mathrm{b}}}\end{array}$ & $\begin{array}{l}\text { Suspension polymerized } \\
\text { Average size: } \\
125 \mu \mathrm{m}\end{array}$ & $\begin{array}{l}\text { Reference: } \mathrm{w} / \mathrm{c}=0.48 \\
\text { SAP: SAP added without extra water. } \\
\mathrm{w} / \mathrm{c}=0.44 ;(\mathrm{w} / \mathrm{c})_{\mathrm{e}}=0.04\end{array}$ & $\begin{array}{l}\text { Salt frost scaling test: } \\
\text { CDF test } \\
\text { Internal damage: } \\
\text { Ultrasonic velocity } \\
\text { measurements }\end{array}$ \\
\hline $\begin{array}{l}{[6]} \\
{[10]^{\mathrm{c}}}\end{array}$ & $\begin{array}{l}\text { Suspension polymerized } \\
\text { 2 SAP products: } \\
\text { - } \quad \text { B }(2 \text { size fractions } \\
\quad(<63 \mu \mathrm{m} ; 63-125 \mu \mathrm{m})) \\
-\quad \mathrm{D}(0-250 \mu \mathrm{m})\end{array}$ & $\begin{array}{l}\text { Reference: } 4 \text { mixes, } \mathrm{w} / \mathrm{c}=0.42(\text { no AEA) and } \mathrm{w} / \mathrm{c}= \\
0.48(\text { no AEA and } 2 \text { different dosages of AEA) } \\
\text { SAP: } 4 \text { mixes, SAP added with extra water: } \\
\mathrm{w} / \mathrm{c}=0.42 \text { or } 0.47(\text { only } D) ;(\mathrm{w} / \mathrm{c})_{\mathrm{e}}=0.04\end{array}$ & $\begin{array}{l}\text { Salt frost scaling test: } \\
\text { CDF test }\end{array}$ \\
\hline [7] & $\begin{array}{l}\text { Suspension polymerized } \\
2 \text { size fractions: } \\
38-63 \mu \mathrm{m} \\
90-125 \mu \mathrm{m}\end{array}$ & $\begin{array}{l}\text { Reference: } w / c=0.42 \\
\text { SAP: One test series for each size of SAP. Each } \\
\text { series include } 5 \text { SAP dosages (see section } 3 \text { ). } \\
\text { SAP added with extra water. }(w / c)_{e} \text { up to } 0.26\end{array}$ & $\begin{array}{l}\text { Salt frost scaling test: } \\
\text { Reference method of } \\
\text { CEN/TS 12390-9 }\end{array}$ \\
\hline [8] & $\begin{array}{l}\text { Suspension polymerized } \\
\text { Average size: } \\
70 \mu \mathrm{m}\end{array}$ & $\begin{array}{l}\text { Reference: Strain-hardening cement-based composite } \\
\text { with PVA fibres. } \\
\text { w/cm }=0.30 ; \mathrm{cm}: 45 \% \text { cement }+55 \% \text { fly ash. } \\
\text { SAP: SAP added both with and without extra water. } \\
\text { In both cases }(\mathrm{w} / \mathrm{cm})_{\mathrm{e}}=0.02 .\end{array}$ & $\begin{array}{l}\text { Salt frost scaling test: } \\
\text { CDF test }\end{array}$ \\
\hline [9] & $\begin{array}{l}\text { Suspension polymerized } \\
\text { Size: } \\
90-150 \mu \mathrm{m}\end{array}$ & $\begin{array}{l}\text { Reference: } 96 \% \text { cement }+4 \% \text { silica fume } \\
\text { w/ceq }=0.40^{\mathrm{d}} \\
\text { AEA, target air content } 4.5 \% \\
\text { SAP: SAP added with extra water } \\
\left(\left(\mathrm{w} / \mathrm{c}_{\mathrm{eq}}\right)_{\mathrm{e}}=0.07\right) \text {, no AEA }\end{array}$ & $\begin{array}{l}\text { Salt frost scaling test: } \\
\text { SS } 137244 \\
\text { Air void analysis: } \\
\text { EN } 480-11\end{array}$ \\
\hline [11] & $\begin{array}{l}\text { Suspension polymerized } \\
2 \text { SAP products: } \\
\text { - } \text { SAP1 }(63-125 \mu \mathrm{m}) \\
\text { - } \text { SAP2 }(0-1.0 \mathrm{~mm}, 63 \% \text { in } \\
\text { range } 250-500 \mu \mathrm{m})\end{array}$ & $\begin{array}{l}\text { Reference: } \mathrm{w} / \mathrm{c}=0.44 \\
\text { SAP: SAP added without extra water } \\
\text { SAP } 1: 3 \text { dosages }\left((\mathrm{w} / \mathrm{c})_{\mathrm{e}}: 0.01-0.04\right) \\
\text { SAP2: }(\mathrm{w} / \mathrm{c})_{\mathrm{e}}=0.05\end{array}$ & $\begin{array}{l}\text { Salt frost scaling test: } \\
\text { ISO/DIS 4846-2 } \\
\text { Internal damage: } \\
\text { Ultrasonic pulse } \\
\text { velocity time } \\
\text { (EN 12504-4) }\end{array}$ \\
\hline [12] & $\begin{array}{l}3 \text { SAP products: } \\
-\quad \text { A; bulk solution } \\
\text { polymerized } \\
\text { - D; suspension polymerized } \\
\quad(100-125 \mu \mathrm{m}) \\
\text { - SAF; SAP fibres, } \varnothing 21 \mu \mathrm{m}, \\
\text { length } 5.8 \mathrm{~mm} \text {. }\end{array}$ & $\begin{array}{l}\text { Reference: } 4 \text { mixes, } w / c=0.40 \text { and } w / c=0.50 \text {, with } \\
\text { and without AEA. } \\
\text { SAP: } 6 \text { mixes (with SAF, D, or one of the following } \\
4 \text { size fractions of A: } 45-63 \mu \mathrm{m}, 63-90 \mu \mathrm{m}, 100-125 \\
\mu \mathrm{m}, 125-200 \mu \mathrm{m}) \text {. } \\
\text { SAP added with extra water. } \\
w / \mathrm{c}=0.42,(\mathrm{w} / \mathrm{c})_{\mathrm{e}}=0.08\end{array}$ & $\begin{array}{l}\text { Salt frost scaling test: } \\
\text { CDF test } \\
\text { Internal damage: } \\
\text { Measurement of } \\
\text { ultrasonic transit time } \\
\text { Air void analysis: } \\
\text { EN } 480-11 \text { and image } \\
\text { analysis }\end{array}$ \\
\hline [13] & $\begin{array}{l}\text { Two types of SAP. } \\
\text { No information regarding } \\
\text { production process and size }\end{array}$ & $\begin{array}{l}\text { Reference: } 80 \% \text { cement and } 20 \% \text { fly ash, } \\
\text { w/cm }=0.42 \text {, with AEA } \\
\text { SAP SAP added with extra water. For each type of } \\
\text { SAP, } 2 \text { mixes are prepared: } 1 \text { with and } 1 \text { without } \\
\text { AEA. } \\
\text { w/cm }=0.42,(\mathrm{w} / \mathrm{cm})_{e}=0.06\end{array}$ & $\begin{array}{l}\text { Internal damage: } \\
\text { ASTM C666, procedure } \\
\text { A }\end{array}$ \\
\hline [14] & $\begin{array}{l}\text { Suspension polymerized } \\
\text { Size: } \\
50-63 \mu \mathrm{m}\end{array}$ & $\begin{array}{l}\text { Reference: } w / \mathrm{c}=0.45 \\
\text { SAP: SAP added with extra water. } 2 \text { test series (SAP } \\
\text { as received and SAP rinsed to remove surfactant). } \\
\text { Each test series comprises } 4 \text { dosages of SAP }\left((\mathrm{w} / \mathrm{c})_{\mathrm{e}}\right. \\
\text { in range } 0-0.06) \text {. }\end{array}$ & $\begin{array}{l}\text { Salt frost scaling test: } \\
\text { Reference method of } \\
\text { CEN/TS 12390-9 } \\
\text { Air void analysis: } \\
\text { EN 480-11 }\end{array}$ \\
\hline
\end{tabular}


1

2

3

4

5

6

7

8

9

10

11

12

13

14

15

16

17

18

19

20

21

22

23

24

25

26

a. SAP size refers to diameter in the dry state.

b. Mönnig and Lura [5] do not make reference to Mönnig [4], but it seems to be the same results that are presented. Here, the summary is mainly based on [5], as this paper describes the experiments in more details than [4].

c. Results from salt frost scaling test are published in [6], but the paper does not specify the mix composition of the tested concrete (reference is made to a publication in German). In [10] mix design, fresh concrete properties as well as results from the salt frost scaling test are stated.

d. $\quad w / c_{e q}=w /(c+1 / 2 \cdot f a+2 \cdot s f)$, w: water; c: cement; fa: fly ash; sf: silica fume (all constituents by mass).

e. It is mentioned that it is the same two types of SAP that are used for a RILEM round robin. If it is the same two types as used in the round robin reported in [22], then SAP1 is a bulk solution polymerized SAP, size: $0-1000 \mu \mathrm{m}\left(\mathrm{d}_{50}: 324 \mu \mathrm{m}\right)$, and SAP2 is a suspension polymerized SAP, size $0-1500 \mu \mathrm{m}\left(\mathrm{d}_{50}: 586 \mu \mathrm{m}\right)$. 


\section{$\underline{\text { General observations }}$}

In most studies it is concluded that SAP improves concrete frost resistance. Concrete with SAP generally performs better than reference concrete without SAP and without air entrainment. The only exception is the highest dosage of SAP1 in [11], where the scaling after 30 freeze/thaw cycles is higher than the scaling of the reference concrete. However, scaling for the two mixes are of the same order of magnitude, and the test surface for each concrete mix is only $78.5 \mathrm{~cm}^{2}$, i.e. less than $10 \%$ of the required test area of the reference method of CEN/TS 12390-9, so the significance of the finding is questionable. When concrete with SAP and no air entrainment is compared to a reference concrete with air entrainment, the concrete with air entrainment typically has the better frost resistance.

The improvement of frost resistance due to SAP addition has been observed both in salt frost scaling tests and in tests, where it is possible to detect internal damage. It has been observed for a variety of concrete mix designs, i.e. $\mathrm{w} / \mathrm{cm}$ in the range $0.30-0.45$, and in mixes with cement as only powder as well as in mixes with supplementary cementitious materials such as fly ash or silica fume. The positive effect of SAP has also been observed for bulk solution polymerized (gel polymerized) SAP as well as for suspension polymerized SAP.

\section{$\underline{\text { The importance of SAP absorption capacity }}$}

It is an open question if SAP should be added with or without extra water. What makes up the true comparison for concrete with SAP: a reference concrete that has w/c equivalent to $(\mathrm{w} / \mathrm{c})_{\text {total }}$ of the concrete with SAP or a reference concrete, where w/c is identical to w/c of the SAP mix? In the study by Brüdern and Mechtcherine [8], SAP was added both with and without extra water. Both SAP mixes showed less scaling than the reference concrete. Of the two SAP mixes, concrete where SAP was added without extra water showed slightly lower 
scaling than the concrete where SAP was added with extra water to compensate SAP moisture absorption in the fresh concrete. This is probably due to the effect of reduced w/c, when SAP is added without extra water. In the study by Reinhardt, Assmann, and Mönnig [6, 10], there were 2 reference mixes. Reference mix with w/c $=0.42$ showed scaling of approx. $1000 \mathrm{~g} / \mathrm{m}^{2}$ after 28 freeze/thaw cycles, whereas reference concrete with $w / c=0.48$ showed scaling of approx. $2500 \mathrm{~g} / \mathrm{m}^{2}$. The two mixes with SAP B $\left(\mathrm{w} / \mathrm{c}=0.42,(\mathrm{w} / \mathrm{c})_{\mathrm{e}}=0.06\right)$ showed scaling of approx. 1000 and $2000 \mathrm{~g} / \mathrm{m}^{2}$, respectively. When comparing with the reference with $\mathrm{w} / \mathrm{c}=$ 0.48 , SAP addition unequivocally reduced salt frost scaling. When comparing to reference with $\mathrm{w} / \mathrm{c}=0.42$, SAP addition had none or even a negative effect on concrete frost resistance. Like this, the conclusion may depend on the choice of reference concrete.

In Table 1, the dosage of dry SAP is not mentioned. Instead the $(w / c) e_{e}$ or $(w / c m)_{e}$ is stated for the mixes in the cited publications. This is because it is assumed that it is the created SAP voids that are important for the frost resistance. The dosage of dry SAP does not hold information on the created SAP void system, but the volume of SAP voids correlates to $(\mathrm{w} / \mathrm{c})_{\mathrm{e}}$. The SAP absorption capacity (g/g dry SAP) is the link between dosage of dry SAP (relative to cement mass) and $(\mathrm{w} / \mathrm{c})_{\mathrm{e}}$. The SAP absorption capacity can be measured in several ways:

- Measurement of SAP absorption in artificial or extracted pore fluid. (Note: For many SAP types the absorption capacity is highly dependent on the ionic strength and ionic composition of the liquid medium. The absorption capacity measured in pure water is much higher than the absorption capacity measured in an ion solution. Therefore, it is misleading to assume that the absorption measured in pure water is representative for SAP placed in fresh concrete.) The measurement may be carried out by observing the swelling 
of a single particle, by the so-called "tea bag method" (which is a gravimetric method that strictly measures water retention instead of water absorption), or by observing the volumetric change of a certain amount of SAP [23].

- Comparison of workability of concrete with SAP, where $(\mathrm{w} / \mathrm{c})_{\text {total }}$ and SAP dosage is known, and workability of concrete mixes without SAP with varying w/c ratios. It is assumed that concrete with SAP after absorption has the same $\mathrm{w} / \mathrm{c}$ as the concrete with similar workability. From the difference between $(w / c)_{\text {total }}$ and w/c, the apparent absorption is calculated. This method is described e.g. in [4].

- Deduction from void analysis of hardened concrete; i.e. comparison of dry SAP particle size and measured SAP void size in hardened concrete or comparison of SAP void volume in hardened concrete and SAP dosage known from mix design [23].

It is difficult to predict the accurate SAP swelling that will take place in concrete. In the studies presented in Table 1, measurements of absorption capacity in artificial pore fluid or derivation from workability measurements are the preferred methods; void analysis of hardened concrete is only performed in few occasions. If the absorption capacity has been measured in more than one way, $(\mathrm{w} / \mathrm{c})_{\mathrm{e}}$ stated in Table 1 is based on measurements in artificial pore fluid. If SAP is added with extra water, it is necessary to know the SAP absorption capacity in advance to calculate the amount of extra water that should be added. However, this is a difficulty, as different methods yield different results, and it is laborious after mixing to check that the assumed absorption has taken place.

The uncertainty associated with the absorption capacity is maybe most exposed, when SAP is added with extra water. In this case it assumed that concrete mixes have identical w/c, but both $\mathrm{w} / \mathrm{c}$ and $(\mathrm{w} / \mathrm{c})_{\text {total }}$ are varying, if the estimated absorption capacity is wrong. If SAP is 
added without extra water, $(\mathrm{w} / \mathrm{c})_{\text {total }}$ is independent of the absorption capacity. However, inaccurate estimates of the absorption capacity is equally problematic, when SAP is added with and without extra water, so in both cases the absorption capacity is an important point of attention.

\section{Air entraining effect of suspension polymerized SAP}

As mentioned, most studies observe that SAP addition improves concrete frost resistance. In continuation of such observations, it is interesting to focus on the explanation for such an effect. All studies listed in Table 1 are fully or partly based on results for concrete with suspension polymerized SAP, and as demonstrated by Laustsen et al. [14], suspension polymerized SAP may contain an air entraining surfactant. Therefore, it is an obvious question, if the effect of SAP addition on frost resistance is due to SAP generated voids or due to an air entraining effect of suspension polymerized SAP (or a third effect, yet to be discovered).

Only in three of the studies $[9,12,14]$, air void analysis has been conducted. Only in these studies it is possible to compare the expected SAP void structure and the actual void structure of the concrete, thereby conjecturing about the amount and void structure of the unintentionally entrained air. However, in several of the studies with suspension polymerized SAP, there are actually indications of extra entrained air:

- In [5] it is mentioned that "The mixing of the concrete containing SAP caused foaming of this mixture". The foaming was attributed to the increased dosage of superplasticizer in the SAP mix, which was necessary to have comparable workability of the two mixes, as SAP was added without addition of extra water. In the paper it is assumed that the air 
bubbles collapsed during compaction and vibration of the moulds. However, some of the air bubbles may have remained in the concrete. The air content measured in the fresh concrete was $1.7 \%$ for the reference mix, and $5.2 \%$ for the SAP mix, respectively. The air content in the fresh concrete does not include the SAP voids, as they are moisture-filled in the fresh concrete. The densities of the hardened concrete were also measured, and the difference in densities of the hardened concrete for the two mixes corresponds to a difference in air content of $1.3 \%$ in the hardened concrete.

- In [6], two different suspension polymerized SAP products were tested, the products being identified as SAP B and SAP D, respectively. The authors noticed that SAP D caused extra air in the fresh concrete. According to [10], the air content in the fresh concrete with SAP D was 4.0-5.4\%, whereas it was only $0.5-1.0 \%$ for mixes with SAP B (same level as reference mixes without an air-entraining admixture, i.e. the natural air content). This indicates that SAP D entrained extra air, whereas SAP B did not.

- In [12] freeze/thaw testing was carried out for concrete with SAP of different origin (bulk solution polymerized SAP, suspension polymerized SAP, and SAP fibres). It was observed during mixing that the suspension polymerized SAP was associated with extra air entrainment (measured air content in fresh concrete: $4.5 \%$ ), and this was confirmed by the air void analysis of the hardened concrete, where the total air content was $6.5 \%$ and the spacing factor $0.22 \mathrm{~mm}$. Based on the amount of SAP in the mix and the absorption capacity, the volume of SAP voids in the hardened concrete was expected to be less than $3.5 \%$.

The majority of the other studies do not mention that extra entrained air has been noted by observation or by direct measurement, but they do not show measurements that can exclude the presence of extra air either. The possible, but not documented, presence of extra entrained 
air voids weakens the conclusions from studies where air void analysis on hardened concrete has not been conducted, as it is not clear if the positive effect of SAP is due to voids created by SAP or extra air voids possibly entrained by surfactant residue. Only in [14], where suspension polymerized SAP has been through a cleaning process to remove the surfactant, and air void analysis has proven that air voids other than SAP voids are negligible (and where SAP is added with extra water, so the effect cannot be put down to reduction of w/c), it seems evident that improved frost resistance can be attributed to voids created by suspension polymerized SAP.

The positive effect of SAP addition on frost resistance is also noted in the study of Assmann [12] for a bulk solution polymerized SAP. Here, the effect of SAP cannot be due to unintended addition of a surfactant used in the SAP production process, as surfactant is not used for production of this type of SAP. However, it is not possible completely to rule out that also bulk solution polymerized SAP can carry components with air entraining effects. This could e.g. be traces of monomer or extractable pieces of polymer, in particular when crushing of the solid gel has led to cleavage of crosslinks. These substances could potentially also influence the formation of air voids. However, in this study, air void analysis of hardened concrete has confirmed that the majority of voids are SAP voids, so also here it seems evident that the improved frost resistance is solely due to voids generated by the SAP particles.

\section{The effect of SAP size on frost resistance}

The relation between air void size and frost resistance has been subject to research for many years. In one of the early studies of concrete frost resistance, Powers in 1945 formulated the following corollary [25]: 
Given a total air space greater than the possible amount of expansion, the protection of concrete will be greater the smaller the average size of the individual air voids.

The mechanism or mechanisms leading to frost deterioration are not yet fully understood. Therefore, it is not known if the relation between air void structure and development of internal frost damage is identical to the relation between air void structure and development of external frost damage. However, for both internal and external frost damage the effect of small, finely distributed voids is indisputable, and therefore the spacing factor concept [26] is often used in both cases.

In [14], it is concluded that SAP voids work as air voids of similar size, so the spacing factor, taking all voids into account (SAP voids and other voids), can be used as indicator for frost resistance. Thus, for equivalent SAP dosages, smaller SAP particles should provide better frost protection than larger SAP particles. This can explain why there in the publications listed in Table 1 seems to be a size effect, where concrete with large SAP particles does not become frost resistant. For example in [13], where a large proportion of the swelled SAP particles presumably are more than $1 \mathrm{~mm}$ in diameter, the concrete with SAP and without AEA degrades during the last 100 of the 300 freeze/thaw cycles of the test method, whereas the reference concrete with air entrainment sustain the test. The concrete with SAP may have a total void volume that is similar to air entrained concrete, but due to the large SAP voids, the spacing factor is much higher than for the air entrained concrete.

In the studies $[6,7,10,12]$ SAP size is one of the variables studied. Among these, the study by Assmann [12] presents the most thorough documentation. The study comprises four different SAP mixes with bulk solution polymerized SAP. The dosage of SAP is the same in 
all four mixes, but the particle size varies. Bulk solution polymerized SAP has an irregular shape in the dry state, leading to SAP voids in the hardened concrete that are non-spherical. As supplement to a traditional air void analysis according to EN 480-11, image analysis of plane sections was performed. The image analysis identified the shape of void cross sections, so it was possible to make separate analysis on SAP voids (voids with irregular shape) and air voids with circular cross sections. In this way it was possible to quantify SAP void sizes and SAP void volume. The image analysis could confirm similar SAP void volume in all four mixes, i.e. differences in absorption capacity could be ruled out as explanation for differences in frost resistance. Therefore, it was expected that mixes with larger SAP particles would show more scaling, as the mixes with larger particles also have the larger spacing factors. This pattern fits for the three of the four mixes with the largest SAP particles, but not for the mix with the smallest SAP particles (45-63 $\mu \mathrm{m}$ in the dry state). This mix shows less scaling than a reference mix without air entrainment, but more scaling than concrete mixes with larger SAP particles. There is no explanation for this observation. From the same mixes, specimens were cast for other types of testing (compressive strength, abrasion resistance), and none of these results indicated that something was wrong with the 45-63 $\mu \mathrm{m}$ mix. Likewise, the image analysis confirms that the large number of small SAP voids is present, so the result from the salt frost scaling test is hard to blame on an erroneous test.

Results that could point in the same direction were presented earlier $[6,10]$. This study is more uncertain, due to the lack of air void analysis of hardened concrete and therefore a potential risk that unintentionally entrained air can influence the result. It showed however that for SAP B, the concrete with SAP $<63 \mu \mathrm{m}$ developed approximately twice as much 
scaling as the concrete with same SAP dosage in the size range 63-125 $\mu \mathrm{m}$ (approximately $2000 \mathrm{~g} / \mathrm{m}^{2}$ and $1000 \mathrm{~g} / \mathrm{m}^{2}$, respectively, after 28 freeze/thaw cycles).

The results of the salt frost scaling tests in $[6,10,12]$ challenges the commonly accepted relation between void size and frost resistance, but it is in line with theories by e.g. Fagerlund [27], which says that voids can become too small, as small air voids will become water-filled and therefore not act as air voids during frost action.

Like this, the relation between SAP void size and frost resistance is still an unresolved question. On one hand, there are indications in the literature that for a constant total SAP void volume, smaller voids offer better frost protection than larger voids. This can explain why there in some studies is observed none or very little effect of SAP addition, as they are based on SAP with large particle size. This can also explain why the frost resistance of concrete with SAP apparently is inferior to the frost resistance of concrete with air entraining agent, as this may be because the SAP void size distribution is coarser than typical air voids in air entrained concrete. On the other hand, there are also indications in the literature that concrete with the smallest SAP voids that otherwise should be the most efficient in ensuring frost protection shows signs of more severe frost damage than concrete with larger SAP voids.

With traditional air entraining agent, it is almost impossible precisely to control void size and total void volume at the same time. SAP technology offers this opportunity, and this makes it a strong future research tool. It seems to be an obvious topic for further research to use SAP to investigate the relation between void size and frost resistance. In most cases, the swollen SAP has the same shape as the dry SAP, it just becomes enlarged, so SAP can in principle be used for research on the relation between void shape and frost resistance, too. If SAP voids 
act as entrained air voids, as pointed out by some studies, this cannot only provide more knowledge about the frost resistance of concrete with SAP, but also knowledge on the relation between air void structure and frost resistance in general.

\section{Experimental Study of Concrete with SAP and Air-entraining Admixture}

At the time of the original experiment reported in [7], the air entraining effect of suspension polymerized SAP was not realized, and it was not considered necessary to conduct air void analysis on hardened concrete. However, when the air entraining effect was discovered in [14], it became clear that it could change the conclusions of [7]. The conclusions of [7] were controversial, as they stated that the frost resistance of concrete with SAP mainly depended on the SAP void volume, not the spacing factor, and as a consequence, for concrete with similar spacing factor, concrete with large SAP voids would show better frost resistance than concrete with smaller SAP voids.

The results reported in [7] originate from a master thesis [24]. The thesis also comprised five mixes with air entraining agent that were not reported in [7]. Small samples of 9 of 10 SAP mixes as well as samples from the reference mix and the air entrained mixes had meanwhile been stored in an archive. Therefore air void analysis according to EN 480-11 could be conducted several years after the original study. It was considered worthwhile to look into the old samples and data again. As can be seen from the literature review, this study with 10 concrete mixes with SAP addition makes it one of the largest studies on frost resistance of concrete with SAP, and as regards the amount of entrained water $(w / c)_{e}$, it spans over a wider range than the other studies. Moreover, though five years have past, studies where the measurements of concrete frost resistance are backed-up with measurements of air void analysis on hardened concrete are still sparse. 
The new data from analysis of hardened concrete is presented in the following. Though most of the experimental details are described in [7] (all except the air void analysis), the experimental procedure is also covered in the present paper, to enable that this paper can be read independently.

\subsection{Materials and Methods}

Table 2 shows the composition of the reference mix in the study:

Table 2: Composition of $1 \mathrm{~m}^{3}$ reference concrete without $S A P(w / c=0.42)$.

\begin{tabular}{|l|l|c|c|c|c|}
\hline Material & Type & $\begin{array}{c}\text { Size } \\
{[\mathrm{mm}]}\end{array}$ & $\begin{array}{c}\text { Density } \\
{\left[\mathrm{kg} / \mathrm{m}^{3}\right]}\end{array}$ & $\begin{array}{c}\text { Mass } \\
{[\mathrm{kg}]}\end{array}$ & $\begin{array}{c}\text { Volume } \\
{\left[\mathrm{m}^{3}\right]}\end{array}$ \\
\hline Cement & CEM I 52.5 & - & 3150 & 390 & 0.124 \\
\hline Water & Tap water & - & 1000 & 164 & 0.164 \\
\hline Sand $^{\mathrm{a}}$ & Sea dredged & $0-4$ & 2601 & 774 & 0.297 \\
\hline Coarse aggregate I $^{\mathrm{a}}$ & Sea dredged & $4-8$ & 2642 & 333 & 0.126 \\
\hline Coarse aggregate II $^{\mathrm{a}}$ & Sea dredged & $8-16$ & 2637 & 722 & 0.274 \\
\hline Entrapped air (estimate) & - & - & - & - & 0.015 \\
\hline
\end{tabular}

a. Aggregates are in saturated, surface dry condition.

The SAP is a covalently crosslinked acrylamide/acrylic acid copolymer, produced by suspension polymerization. The density of the dry SAP is approximately $1500 \mathrm{~kg} / \mathrm{m}^{3}$, and the absorption capacity in synthetic pore fluid is $12.5 \mathrm{~g} / \mathrm{g}$. The dry SAP was by sieving divided into size fractions 38-63 $\mu \mathrm{m}$ and 90-125 $\mu \mathrm{m}$. The absorption capacity corresponds to that the SAP particle diameter increases with a factor of 2.65 , when the dry SAP gets in contact with water in the fresh concrete, and therefore the two size fractions were expected to result in SAP 
voids with diameters of approximately $150 \mu \mathrm{m}$ and $300 \mu \mathrm{m}$, respectively. The swelled diameter is used to identify mixes.

The mixes with SAP were identical to the reference concrete, except from addition of dry SAP and extra water to compensate the absorption of SAP. For each SAP size, five different dosages were tested. For the small SAP size, dosages corresponded to 1-10\% SAP void volume relative to the paste volume of the concrete. For the larger SAP size, dosages corresponded to $5-35 \%$ SAP void volume relative to paste volume.

The five mixes with air entrainment were identical to the mix presented in Table 2, except from the use of air entraining agent, which resulted in air contents in the fresh concrete in the range $2.4-6.0 \%$.

Slump and total air content were measured for the fresh concrete according to methods EN 12350-2 [28] and EN 12350-7 [29] (results were not published in [7]).

Salt frost scaling test was carried out according to the reference method of CEN/TS 12390-9 [17]. A rubber sleeve was mounted on all specimens (Ø150 x $50 \mathrm{~mm}$ cylindrical specimens). The sleeve made it possible to establish a water reservoir on top of the specimen. When the specimen was 28 days old, it was first subject to 3 days of capillary suction, by placing demineralized water in the reservoir. On the $31^{\text {st }}$ day after casting, the demineralized water was replaced by $3 \% \mathrm{NaCl}$ solution, and freeze/thaw action started. The specimens were placed in a freezing cupboard, which performed a freeze/thaw cycle going from $+20^{\circ} \mathrm{C}$ to $-20^{\circ} \mathrm{C}$ and back to $+20^{\circ} \mathrm{C}$ every 24 hours. The test was continued for 56 freeze/thaw cycles, 
1

2

3

4

5

6

7

8

where scaled material was collected from the test surface after 7, 14, 28, 42, and 56 freeze/thaw cycles.

\subsection{Results}

Mixes with air entraining agent are labeled according to the air content in fresh concrete in $\%$ (for example: AEA-2.4). The SAP mixes are labeled according to SAP size and SAP dosage in $\%$ of cement mass (for example $150 \mu \mathrm{m}$ SAP-0.06).

The results of the measurements of fresh concrete properties are shown in Figs. 2 and 3:

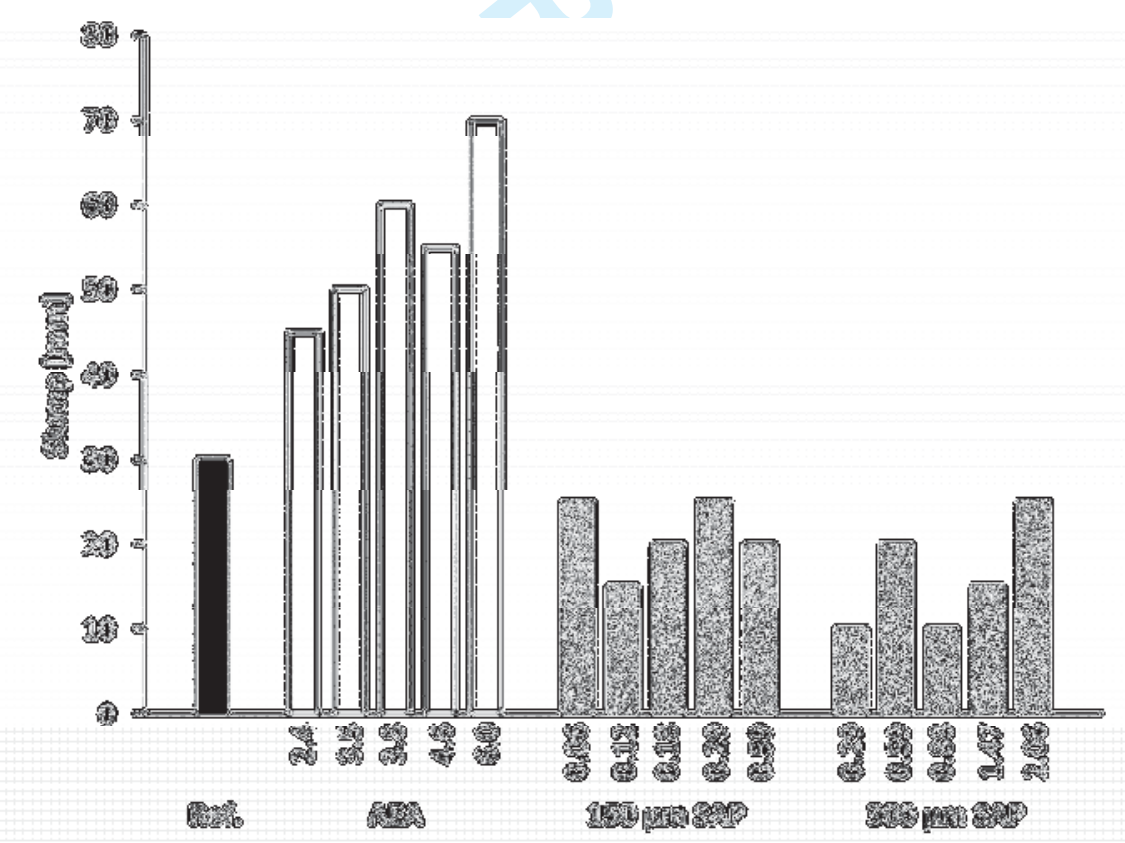

Fig. 2: Measured slump according to EN 12350-2. 


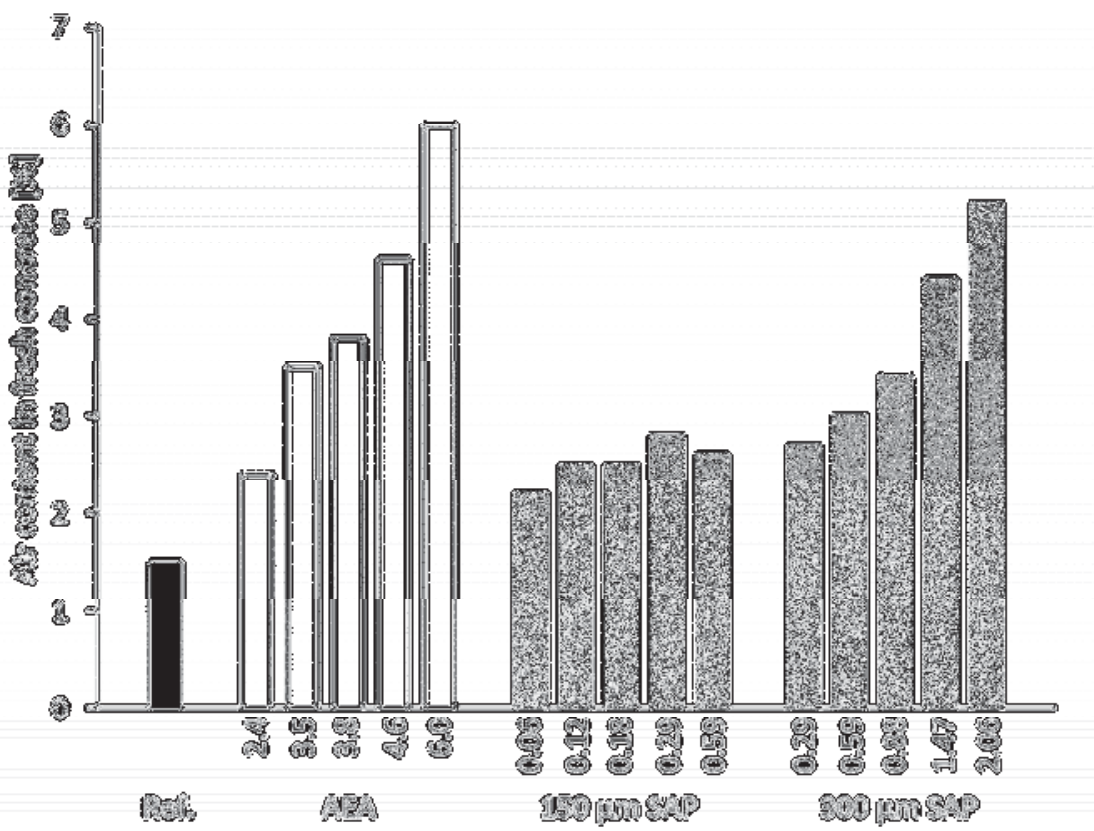

Fig. 3: Air content in fresh concrete measured according to EN 12350-6 (pressure method).

The results of tests on hardened concrete are shown in Table 3: 
Table 3: Results from tests of hardened concrete (A: total air content, S: specific surface, L: spacing factor).

\begin{tabular}{|c|c|c|c|c|c|c|c|}
\hline & \multicolumn{3}{|c|}{$\begin{array}{c}\text { Theoretical air void } \\
\text { parameters, } \\
\text { SAP voids only }\end{array}$} & \multicolumn{3}{|c|}{ Measured air void parameters } & \multirow{2}{*}{ 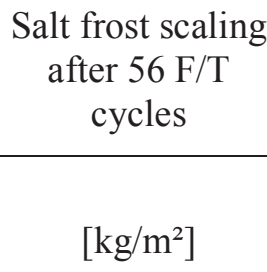 } \\
\hline & $\begin{array}{c}A \\
{[\%]}\end{array}$ & $\begin{array}{c}S \\
{\left[\mathrm{~mm}^{-1}\right]}\end{array}$ & $\begin{array}{c}L \\
{[\mathrm{~mm}]}\end{array}$ & $\begin{array}{c}A \\
{[\%]}\end{array}$ & $\begin{array}{c}S \\
{\left[\mathrm{~mm}^{-1}\right]}\end{array}$ & $\begin{array}{c}L \\
{[\mathrm{~mm}]}\end{array}$ & \\
\hline \multicolumn{8}{|c|}{ Without SAP and AEA } \\
\hline Ref. & - & - & - & 1.6 & 12 & 0.72 & 2.97 \\
\hline \multicolumn{8}{|c|}{ AEA } \\
\hline 2.4 & - & - & - & 3.0 & 24 & 0.26 & 0.10 \\
\hline 3.5 & - & - & - & 3.1 & 24 & 0.25 & 0.03 \\
\hline 3.8 & - & - & - & 5.0 & 27 & 0.18 & 0.06 \\
\hline 4.6 & - & - & - & 4.8 & 31 & 0.16 & 0.06 \\
\hline 6.0 & - & - & - & 7.7 & 30 & 0.12 & 0.02 \\
\hline \multicolumn{8}{|c|}{$150 \mu \mathrm{m}$ SAP } \\
\hline 0.06 & 0.29 & 24 & 0.36 & missing & missing & missing & 0.58 \\
\hline 0.12 & 0.58 & 24 & 0.28 & 2.4 & 13 & 0.50 & 0.21 \\
\hline 0.18 & 0.86 & 24 & 0.24 & 2.9 & 15 & 0.42 & 0.21 \\
\hline 0.29 & 1.44 & 24 & 0.19 & 3.0 & 22 & 0.29 & 0.16 \\
\hline 0.59 & 2.88 & 24 & 0.14 & 3.7 & 20 & 0.27 & 0.13 \\
\hline \multicolumn{8}{|c|}{$300 \mu \mathrm{m} \mathrm{SAP}$} \\
\hline 0.29 & 1.44 & 12 & 0.40 & 3.2 & 20 & 0.30 & 0.19 \\
\hline 0.59 & 2.88 & 12 & 0.30 & 5.5 & 17 & 0.28 & 0.14 \\
\hline 0.88 & 4.31 & 12 & 0.25 & 7.3 & 19 & 0.20 & 0.10 \\
\hline 1.47 & 7.19 & 12 & 0.20 & 9.8 & 22 & 0.12 & 0.11 \\
\hline 2.06 & 10.06 & 12 & 0.15 & 12.5 & 22 & 0.09 & 0.10 \\
\hline
\end{tabular}




\subsection{Discussion}

As expected, the air content in the fresh concrete with air entraining agent increases, as the dosage of air entraining agent is increased. Increase of dosage of air entraining agent also increases the measured slump. For the $150 \mu \mathrm{m}$ SAP mixes, the air content in the fresh concrete is almost identical (2.2-2.8\%), the level being slightly higher than the air content measured in the reference mix (1.6\%). For $300 \mu \mathrm{m}$ mixes, the air content in the fresh concrete increases with increasing SAP dosage (from $2.7 \%$ to $5.2 \%$ ). Clearly there was an indication of extra entrained air in the SAP mixes. However, as the risk of extra entrained air was not realized at the time of testing, the increase in air content in the fresh concrete was interpreted as a result of poor workability. The SAP mixes were all stiffer than the reference mix. In the two mixes with the highest SAP dosages (300 $\mu \mathrm{m}$ SAP-1.47 and SAP-2.06), extra water had to be added, so the w/c for these mixes became 0.45 ; without the extra water, the mixes were too stiff for casting.

Fig. 4 shows a comparison between air content measured in the fresh concrete and in the hardened concrete. 


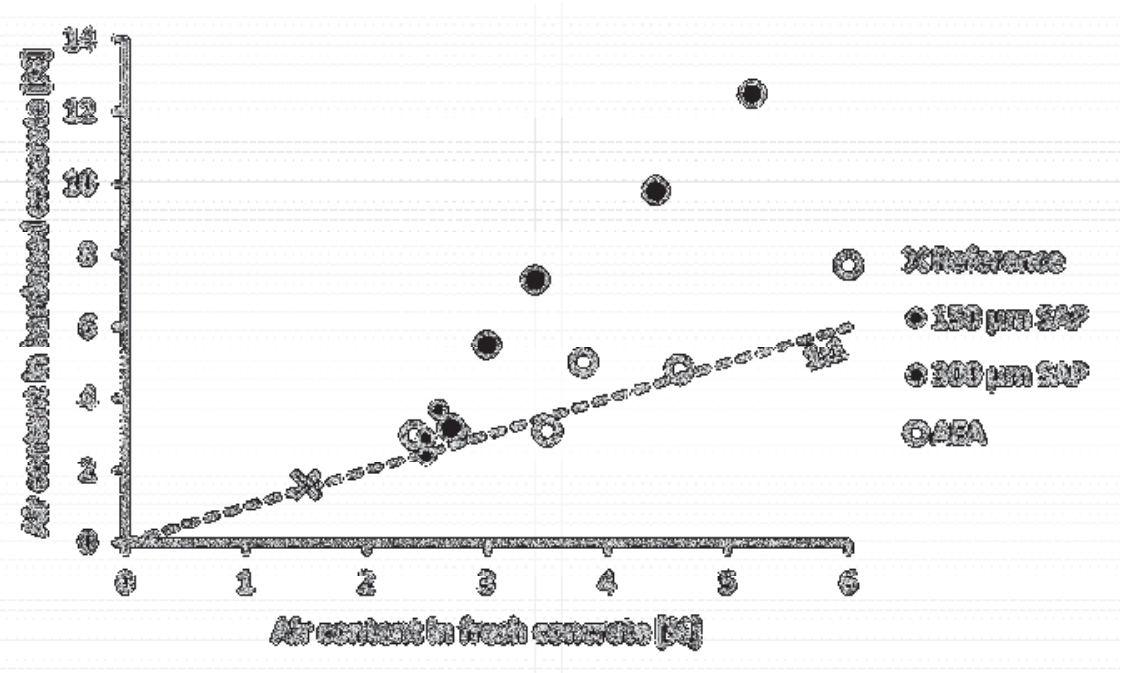

Fig. 4: Relation between air content in fresh and hardened concrete.

In Fig. 4, it seems like there is an almost 1-to-1 relation for air content in fresh concrete and in hardened concrete for the reference mix and the mixes with air entraining agent. For mixes with SAP, the air content measured in the hardened concrete is higher than what is measured in the fresh concrete. This is to be expected, as the SAP voids are liquid-filled in the fresh concrete and therefore their volume is not measured by the pressure-meter test.

If the volume of air voids, i.e. voids other than SAP voids, are measured correctly in the fresh concrete, then the difference between total air content of hardened concrete and total air content in the fresh concrete can be related to the absorption capacity of SAP, see Fig. 5. 


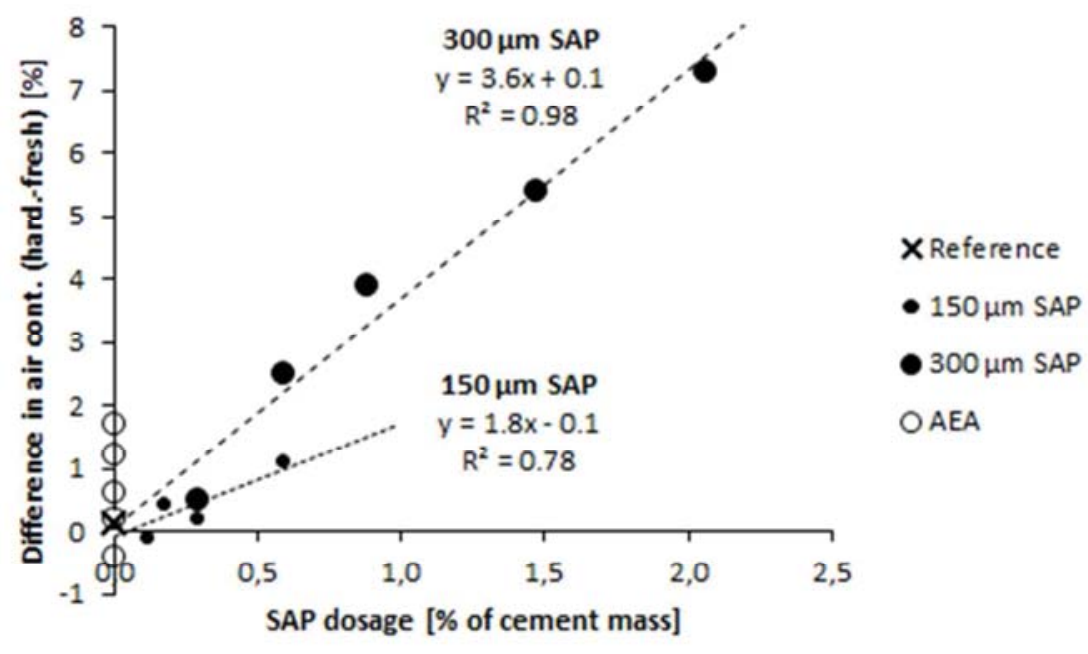

Fig. 5: Difference between air content measured in hardened concrete and in fresh concrete, respectively, mapped as a function of SAP dosage.

In Fig. 5 the point of the reference mix is included in calculation of the regression lines, corresponding to having a point where the SAP dosage is $0 \%$ in each SAP series. For $300 \mu \mathrm{m}$ SAP the regression line shows a clear trend. For each $\%$ of SAP relative to cement mass, a SAP void volume is created equivalent to $3.6 \%$ of the concrete volume. This corresponds to a SAP absorption capacity of $8.6 \mathrm{~g} / \mathrm{g}$, i.e. significantly lower than the anticipated $12.5 \mathrm{~g} / \mathrm{g}$. For $150 \mu \mathrm{m}$ SAP, the created SAP volume is lower; $1.8 \%$ of concrete volume for each $\%$ of SAP relative to cement mass. As indicated by the $\mathrm{R}^{2}$ - values, the result for $150 \mu \mathrm{m}$ SAP is more uncertain than the result for $300 \mu \mathrm{m}$ SAP. This is because the $150 \mu \mathrm{m}$ SAP series spans a much smaller dosage interval, and therefore measuring uncertainties become more pronounced.

The SAP dosages of the present study are relatively high. A SAP dosage of $2.06 \%$ and an absorption capacity of $12.5 \mathrm{~g} / \mathrm{g}$ corresponds to $(\mathrm{w} / \mathrm{c})_{\mathrm{e}}=0.26$, i.e. much higher than in mixes in any other study presented in Table 1. Due to the high SAP dosages, the present study also 
1

2

3

4

5

6

7

8

9

10

11

becomes more sensitive to a faulty estimate of the absorption capacity. If the absorption capacity is $8.6 \mathrm{~g} / \mathrm{g}$ instead of $12.5 \mathrm{~g} / \mathrm{g}$, this corresponds to a change in actual w/c of 0.08 for the $300 \mu \mathrm{m}$ SAP-2.06 mix.

Figs. 6 and 7 show the cumulated scaling after 56 freeze/thaw cycles. In Fig. 6, the scaling is plotted as a function of the theoretical spacing factor. The theoretical spacing factor is calculated from the expected average size of the swollen SAP and the expected total volume of SAP voids, assuming an absorption capacity of $12.5 \mathrm{~g} / \mathrm{g}$. Hence it is only possible to calculate a theoretical spacing factor for concrete mixes with SAP. In Fig. 7, the scaling is plotted as a function of the measured spacing factor, and here, there are measurements for SAP mixes as well as the reference and concrete mixes with air entraining agent.

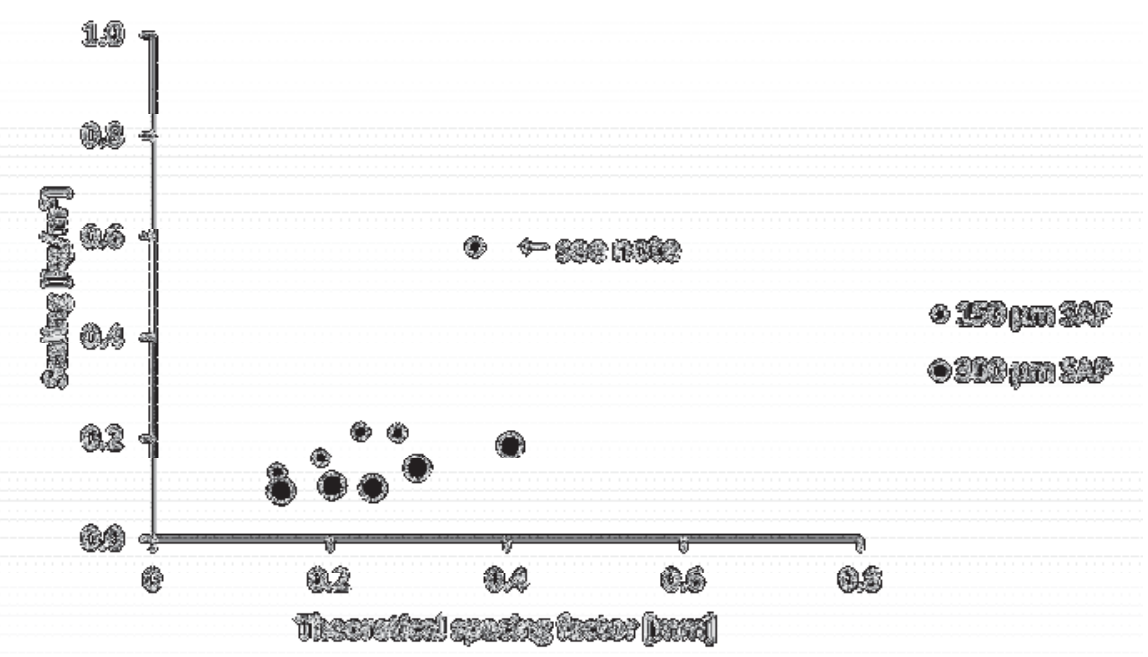

Fig. 6: Salt frost scaling after 56 freeze/thaw cycles vs. the theoretical spacing factor calculated from the expected SAP voids. Note: Sample from this mix was lost, so air void analysis on hardened concrete has not been carried out for this mix. 


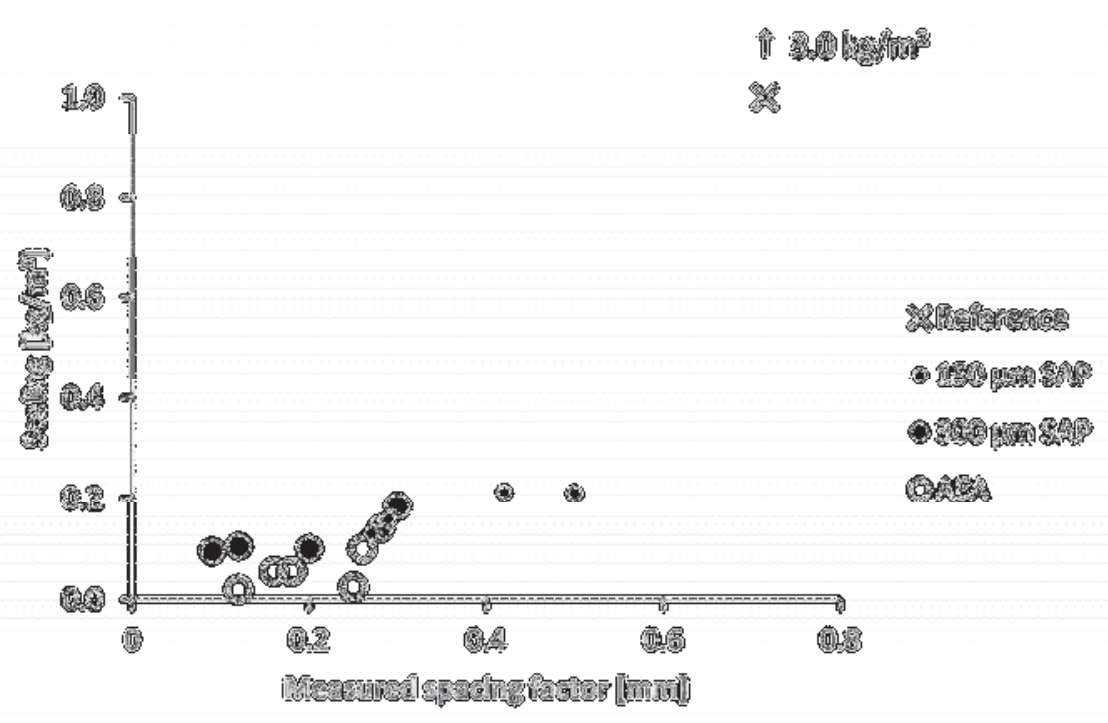

Fig. 7: Salt frost scaling after 56 freeze/thaw cycles vs. the spacing factor measured on polished, color impregnated plane sections of hardened concrete.

A figure similar to Fig. 6 was also published in [7]. The figure indicates that for a certain spacing factor, concrete with $300 \mu \mathrm{m}$ SAP seems to have better frost resistance, i.e. less scaling, than concrete with $150 \mu \mathrm{m}$ SAP. This indicates a size effect that the spacing factor does not account for. This was also the conclusion drawn in [7].

The difference between $150 \mu \mathrm{m}$ SAP and $300 \mu \mathrm{m}$ SAP has disappeared in Fig. 7. Here, it looks like the scaling results for all SAP mixes may belong to the same trend line. There is no longer basis for arguments in favor of a size effect.

At low spacing factors, the mixes with air entraining agent show less scaling than concrete with SAP. The three SAP mixes with spacing factors lower than $0.20 \mathrm{~mm}$ are all $300 \mu \mathrm{m}$ SAP mixes with high SAP dosages, so here the difference between SAP mixes and air entrained mixes probably are due to differences in w/c, as explained earlier in this section. It seems 
likely that if $\mathrm{w} / \mathrm{c}$ of all mixes had been comparable, then SAP mixes and air entrained mixes would have followed the same trend line. As the measured spacing factor both takes SAP voids and other voids into account, Fig. 7 seems to support the statement that SAP voids work as air voids, which was the conclusion of [14].

In the swollen state, the $150 \mu \mathrm{m}$ SAP particles in the present study have a size comparable to the smallest SAP size in the study by Assmann [12]. On one hand, the present study cannot confirm the finding of Assmann, saying that a certain addition of very small SAP particles is less effective in improving frost resistance than the same addition of slightly larger SAP particles. On the other hand, the present study cannot disprove the finding of Assmann either. In the present study, it is not possible to isolate the effect of SAP voids; the observed salt frost scaling is the result of a combined effect of SAP voids and entrained air voids due to surfactant on SAP, and the effect of entrained air voids may even be the dominating effect. To examine a possible size effect of SAP voids, it is necessary to set up a study, where the effect of SAP voids on frost resistance is not over-shadowed by the effect of other voids.

\section{Conclusion}

The literature review and the experimental study presented in this paper point in the same direction:

- It is clearly demonstrated that SAP addition can improve the frost resistance of concrete, compared to concrete without SAP and air entraining agent. This is both the case, when SAP is added with and without extra water to counterbalance the SAP water absorption in the fresh concrete. In the first case, the improved frost resistance depends on the voids 
created by the SAP. In the latter case, the improvement of frost resistance is a result of both the voids created by SAP and the lowering of w/c due to SAP absorption.

- When studying the influence of SAP on concrete properties, it is vital to keep track of the SAP voids, i.e. to document their existence (sizes and number) in the hardened concrete. Not doing so, i.e. assuming a certain SAP void structure in the hardened concrete extrapolated from SAP dosage, particle size of dry SAP and SAP absorption capacity, entails large uncertainties for the conclusions. This is true for all concrete properties that depend on concrete air content. However, it is especially true for frost resistance, as this property is very closely linked to the void structure of the concrete. The importance of documenting the voids in the hardened concrete is true for all types of SAP, but especially for suspension polymerized SAP. This type of SAP may hold small amounts of surfactant used in the production process and therefore the use of suspension polymerized SAP involves a risk of getting extra entrained air. The extra entrained air may significantly change the performance of the concrete.

- The basic premise for the spacing factor concept, which states that for a certain total void volume smaller voids are more effective than larger voids in providing frost protection, seems to be true for SAP voids. However, some studies point to that there is a lower size limit for this assumption; the smallest SAP voids do not contribute to frost protection or at least they contribute to a less extent than larger voids. The experimental study of the present paper could not confirm or deny this aspect, so more research is needed. Voids created by SAP seem to work as entrained air voids of similar size. If this is true, research carried out with SAP will not only improve our knowledge about frost resistance of concrete with SAP, it will improve our knowledge on the relation between void structure and frost resistance in general. 


\section{Acknowledgement}

The air void analyses of the hardened concrete were made possible with financial support from the COWI Foundation. This support is greatly acknowledged.

\section{References}

1. Buchholz FL, Graham AT (1998) Modern superabsorbent polymer technology. John Wiley \& Sons, New York

2. Jensen OM, Hansen PF (2001) Water-entrained cementbased materials: I. Principles and theoretical background. Cem Concr Res 31:647-654

3. Kennedy HL (1943) The function of entrained air in concrete. ACI Journal Proceedings $39: 529-544$

4. Mönnig S (2005) Water saturated super-absorbent polymers used in high strength concrete. Otto Graf Journal 16:193-202

5. Mönnig S, Lura P (2007) Superabsorbent polymers - An additive to increase freeze-thaw resistance of high strength concrete. Adv Constr Mater Part V:351-358

6. Reinhardt H-W, Assmann A, Mönnig S (2008) Superabsorbent polymers (SAPs) —an admixture to increase the durability of concrete. In: Sun W, Breugel Kv, Miao C, Ye G, Chen H (eds) Microstructure related durability of cementitious composites, RILEM Proceedings PRO 61, pp 313-322

7. Laustsen S, Hasholt MT, Jensen OM (2008) A new technology for air-entrainment of concrete. In: Sun W, Breugel Kv, Miao C, Ye G, Chen H (eds) Microstructure related durability of cementitious composites, RILEM Proceedings PRO 61, pp 1223-1230

8. Brüdern AE, Mechtcherine V (2010) Multifunctional use of SAP in Strain-hardening Cementbased Composites. International RILEM Conference on Use of Superabsorbent 
Polymers and Other New Additives in Concrete, Technical University of Denmark, Lyngby, RILEM Proceedings PRO 74, 11-22

9. Hasholt MT, Pade C (2011) Concrete with superabsorbent polymers (SAP) - experience from the Fehmarn field exposure station in Rødbyhavn. In: Proceedings of XXI Nordic Concrete Research Symposium, 2011, Hämeenlinna, Finland, 343-346

10. Reinhardt, H-W, Assmann A (2012) Effect of superabsorbent polymers on durability of concrete. Chapter 9 in Mechtcherine V, Reinhard H-W (eds) Application of superabsorbent polymers (SAP) in concrete construction. State of the Art Report prepared by RILEM Technical Committee 225-SAP. Springer, Heidelberg

11. Craeye B, Tielemans T, Lauwereijssens G, Stoop J (2013) Effect of super absorbing polymers on the freeze-thaw resistance of coloured concrete roads. Road Materials and Pavement Design, 14:90-106

12. Assmann A (2013) Physical properties of concrete modified with superabsorbent polymers, University of Stuttgart, Ph.D. thesis

13. Jones WA, Weiss WJ (2014) Freeze thaw durability of internally cured concrete made using superabsorbent polymers. In: Proceedings of the $4^{\text {th }}$ International conference on the Durability of concrete Structures, July 2014, West Lafayette, USA: 3-11

14. Laustsen S, Hasholt MT, Jensen OM (2015) Void structure of concrete with superabsorbent polymers and its relation to frost resistance. Materials and Structures $48: 357-368$

15. Laustsen S (2011) Engineered air-entrainment of concrete. Technical University of Denmark, Ph.D. thesis

16. Powers TC (1975) Freezing effects in concrete. In: Proceedings 'Durability of Concrete', ACI SP-47, American Concrete Institute, Detroit, USA: 1-11 
1

2

3

4

5

6

7

8

9

10

11

17. DS/CEN/TS 12390-9 (2006) Testing of hardened concrete - Part 9: Freeze-thaw resistance - scaling, Danish Standards

18. SS 137244 (2005) Concrete testing - Hardened concrete - Scaling at freezing (in Swedish), Swedish Standards Institute

19. Setzer MJ, Fagerlund G, Janssen DJ (1996) CDF test - Test method for the freeze-thaw resistance of concrete - tests with sodium chloride solution (CDF) - Recommendation. Materials and Structures 29:523-528

20. DS/EN 4801-11 (2005) Admixtures for concrete, mortar and grout - Test methods - Part 11: Determination of air void characteristics in hardened concrete, Danish Standards

21. ASTM C457 (2012) Standard test method for microscopical determination of parameters of the air-void system in hardened concrete, ASTM International

22. Mechtcherine V, et al. (2014) Effect of internal curing by using superabsorbent polymers (SAP) on autogenous shrinkage and other properties of a high-performance fine-grained concrete: results of a RILEM round-robin test. Materials and structures 47:541-562

23. Jensen OM (2011) Water absorption of superabsorbent polymers in a cementitious environment. In: Proceedings of International RILEM Conference on Advances in Construction Materials through Science and Engineering, 2011, Hong Kong, China, 22-35

24. Laustsen S, Møller AM (2007) Kontrolleret luftindblanding i beton (in Danish). Technical University of Denmark, Master thesis

25. Powers TC (1945) A working hypothesis for further studies of frost resistance of concrete. ACI Journal Proceedings 41:245-272 (reprinted as PCA Bulletin no. 5)

26. Powers TC (1949) The air requirement of frost-resistant concrete. Proceedings of the Highway Research Board 29 (reprinted as PCA Bulletin no. 33)

27. Fagerlund G (1994) Predicting the service life of concret exposed to frost action through a modelling of the water absorption process in the air-pore system. Report TVBM-7085, 
1

2

3

4

5

6

7

8

9

10

11

Lund University (contribution to RILEM/NATO Workshop on The modelling of

Microstructure and its Potential for Studying Transport Properties and Durability, 1994, St. Rémy-les-Chevreuse, France)

28. DS/EN 12350-2 (2002) Testing fresh concrete - Part 2: Slump-test, Danish Standards 29. DS/EN 12350-7 (2002) Testing fresh concrete - Part 7: Air content - Pressure methods, Danish Standards 